\title{
A atualidade dos conceitos freudianos de eu ideal, Ideal do eu e supereu
}

\section{The actuality of Freud's concepts of ideal ego, ego ideal and superego}

\section{La actualidad de los conceptos freudianos del Yo ideal, ideal del Yo y Superyo}

\author{
Andréa Di Pietro Lewkovitch* \\ Universidade Federal do Rio de Janeiro - UFRJ, Rio de Janeiro, Rio de Janeiro, Brasil
}

\section{Angélica Bastos de Freitas Rachid Grimberg**}

Universidade Federal do Rio de Janeiro - UFRJ, Rio de Janeiro, Rio de Janeiro, Brasil

\begin{abstract}
RESUMO
O presente artigo aborda as identificações constitutivas do sujeito e o imperativo superegoico a partir do referencial psicanalítico, com o objetivo de examinar a pertinência e atualidade deste aparato conceitual. A pesquisa deteve-se na questão do narcisismo parental para tratar o papel da fantasia dos pais na formação dos ideais, chegando à concepção do supereu enquanto imperativo de gozo, dimensão que ultrapassa as identificações parentais. Recorremos à autobiografia do tenista Andre Agassi, apresentada no livro escrito após o término de sua carreira profissional. Ele relata ter sido, desde a infância, obrigado por seu pai a praticar tênis, ainda que declarasse incessantemente seu ódio por tal esporte. Não conseguia parar de jogar tênis, e, assim, tornou-se um dos maiores tenistas da história. Considerando as limitações impostas por um relato que não constitui um caso clínico, o conflito trazido por Agassi presta-se a traçar um percurso a respeito da formação dos ideais e da função do supereu na economia psíquica de acordo com a teoria psicanalítica.
\end{abstract}

Palavras-chave: Psicanálise, Freud, eu, Ideal, supereu.

\begin{abstract}
This article deals with the constitutive identifications of the subject and the superegoic imperative, from the psychoanalytic perspective, with the purpose of examining the pertinence and actuality of this conceptual apparatus. The research centered on the issue of parental narcissism to deal with the role of parents' fantasy in the formation of the ideals, arriving to the conception of the superego while imperative of juissance, dimension which surpasses the parental identifications. We resorted to the autobiography of the tennis player Andre Agassi, presented in the book written at the end of his professional career. He reports that, since childhood, he had been forced by his father to practice tennis, even though he unceasingly declared his hatred for the sport. He could not stop playing tennis and, therefore, became one of the biggest tennis players of history.
\end{abstract}


Considering the limitations imposed by a report that does not constitute a clinical case, the conflict brought by Agassi serves to outline a path regarding the formation of the ideals and the role of the superego in the psychic economy in accordance with the psychoanalytic theory.

Keywords: Psychoanalysis, Freud, ego, ideal, superego.

\section{RESUMEN}

El presente artículo aborda las identificaciones constitutivas del sujeto y el imperativo superyoico desde una perspectiva psicoanalítica, con el objetivo de verificar la pertinencia y actualidad de este aparato conceptual. La investigación se detiene en la cuestión del narcisismo parental para tratar el papel de la fantasía de los padres en la formación de los ideales, llegando al concepto del superyó en la vertiente del imperativo de goce, dimensión que va más allá de las identificaciones paternas. Recorremos la autobiografía del tenista André Agassi, presentada en su libro después del final de su carrera profesional. Este relata haber sido, desde niño, obligado por su padre a practicar tenis, a pesar de haber declarado de manera incesante su odio por este deporte. No consiguió parar de jugar al tenis y de este modo se convirtió en uno de los mayores tenistas de la historia. Teniendo en cuenta las limitaciones impuestas por un relato que no constituye un caso clínico, el conflicto traído por Agassi se presta para trazar un recorrido por la formación de los ideales y de la función del Superyó en la economía psíquica, de acuerdo con la teoría psicoanalítica.

Palabras-clave: Psicoanálisis, Freud, Yo, Ideal, superyó.

\section{Introdução}

O tempo presente encontra-se marcado por um declínio dos ideais ditos paternos em proveito da ascensão dos objetos engendrados na aliança entre o discurso da ciência e o capitalismo. Essa conjuntura não implica em dispensar conceitos como o de identificação, mas requer a verificação de sua operatividade. A erosão de tais ideais simbólicos cede lugar a identificações horizontais e imaginárias, que regem o agrupamento dos falantes em torno de características compartilhadas, tais como anorexias, hiperatividade, depressão, dentre outros, enquanto os objetos da tecno-ciência impõem-se, de acordo com a incidência do mercado sobre os sujeitos e os corpos. Essa configuração promove ideais sociais de desempenho e saúde, em detrimento do desejo.

O objetivo deste trabalho consiste em examinar a pertinência e a atualidade dos conceitos de identificação simbólica, bem como sua articulação com o imaginário e o supereu. Para tal, valemo-nos de um relato autobiográfico recente, no qual um profissional do esporte testemunha o mal-estar experimentado ao longo de sua carreira. Este procedimento metodológico inspira-se na análise efetuada por $\mathrm{S}$. Freud (2006a) com base no relato autobiográfico do Presidente Schreber, com quem o psicanalista jamais se encontrou. No trabalho realizado com o texto de Agassi, busca-se circunscrever elementos que permitam situar os instrumentos conceituais, sem, no entanto, 
proceder a interpretações que só seriam possíveis no contexto de um tratamento psicanalítico e, por conseguinte, sob transferência.

\section{A autobiografia}

"Jogo o tênis para viver, embora deteste esse esporte. Detesto o tênis com uma paixão secreta e sombria. E sempre detestei." (Agassi, 2010, p.10). É dessa maneira que Andre Agassi, um dos maiores tenistas da história do esporte, apresenta seu conflito em sua autobiografia, publicada após o encerramento de sua carreira. Em seu relato, ele conta que, por imposição de seu pai, seus treinamentos intensivos iniciaram-se quando ele tinha apenas quatro anos e que sempre odiou jogar tênis. Durante sua adolescência, Agassi encontrou diferentes maneiras de apresentar sua revolta com a prática esportiva intensiva a que era submetido - usou roupas extravagantes, colocou piercings, deixou que suas unhas crescessem e pintou-as de vermelho, bebeu litros de uísque, entre outras coisas. Mais tarde, já atleta profissional, usou drogas, perdeu partidas de propósito e chegou a doar suas raquetes, afirmando por várias vezes que deixaria o esporte que tanto odiava.

Devido às extravagâncias e à sua rebeldia, imprensa e torcedores atribuíram ao tenista, de forma crítica e hostil, um slogan, dito por ele em um comercial: imagem é tudo. Aqui, acompanharemos o depoimento de Agassi atentos ao que ele pode nos ensinar e pensaremos de que forma essa imagem - que não era tudo, mas certamente era muito - se constituiu, e para isso é preciso ir além dela.

\section{3 "His Majestry, the Baby"}

Um pai marcado por sua austeridade e sua determinação em fazer do tênis a profissão de seu filho mais novo ocupa um importante lugar no testemunho de Andre Agassi. Como nos conta, desde antes de seu nascimento, seu pai havia decidido que ele seria o tenista número um do mundo. Ainda quando ele era bebê, o pai prendia uma raquete de pingue-pongue em sua mão e o estimulava a bater no móbile de bolinhas de tênis que pendurara acima do berço do filho. Tal investimento somado ao fato de o pai de Agassi ter sido um boxeador que teve sua carreira esportiva frustrada remetem-nos ao que Freud definiu como sendo o narcisismo parental.

O conceito de narcisismo foi definido por Freud (2004) como o estádio seguinte ao auto-erotismo, quando o eu se constitui e tornase, ele próprio, alvo de investimento libidinal. Posto que o eu é também tomado como alvo das pulsões sexuais e somente uma parte 
delas é enviada aos objetos - apesar de essencialmente permanecer no eu - foi preciso que Freud estabelecesse uma nova dualidade pulsional, entre libido do eu e libido do objeto, como uma amplificação daquela que opunha as pulsões do eu (de autoconservação) às pulsões sexuais (libido).

A primeira via de acesso de Freud ao narcisismo foi o estudo das parafrenias, mais especificamente dos fenômenos de delírio de grandeza próprios desses estados e da perda de interesse nas coisas e pessoas do mundo. Ao contrário do neurótico, que ao distanciar-se do mundo exterior preserva o investimento nos objetos em sua fantasia, o parafrênico recolhe sua libido das pessoas e das coisas (sem substituí-las por objetos imaginários) e a direciona ao eu, o que se evidencia no delírio de grandeza. Esse delírio nada mais é do que a amplificação de um estado narcísico que já existia antes.

Esse estado narcísico que Freud chamou de inicial, ele apenas supôs existir por meio da observação da atitude afetuosa dos pais para com seu bebê, que não é outra coisa senão uma revivescência do próprio narcisismo dos pais, outrora abandonado. O bebê, tendo a ele atribuída toda a perfeição, é aquilo que os pais fazem dele, e tem para si reivindicados os direitos aos quais os pais tiveram que renunciar: "His Majesty the Baby" (Sua Majestade o Bebê), Freud nos diz.

No entanto, o relato de Agassi nos faz ir além da questão do narcisismo parental e não atribuir somente a seu pai os motivos que o levaram a jogar tênis por mais de trinta anos. A própria história dos três irmãos mais velhos do tenista aponta para o aspecto fantasmático da falta de escolha de que Agassi se queixa. Todos eles foram também obrigados pelo pai a jogar tênis, mas viveram essa situação de maneiras diferentes e tiveram outra saída: abandonaram o esporte logo cedo.

Agassi, por outro lado, precisou de um limite dado pelo corpo para se aposentar, precisou chegar ao ponto em que não conseguia mais jogar. Mais do que isso: ao ponto em que quase não conseguia mais respirar. Segundo ele, seu corpo diz, aos gritos, que não quer mais jogar tênis: suas duas hérnias de disco e "um osso que não parava de crescer" obstruíram seus nervos inflamados, que o impediam de respirar. Dividido muitas vezes entre "tomara que isto acabe logo" e "não estou preparado para que isto acabe", Agassi era ameaçado no nível do real, traumático: "não consigo deixar de sentir que estou à beira da morte" (Agassi, 2010, p. 15).

Em seu escrito Observação sobre o relatório de Daniel Lagache (1998), Lacan sublinha a passagem em que Lagache afirma que antes do nascimento a criança já é um pólo de expectativas, projetos e atributos, e observa que talvez seja sob o acúmulo deles que o sujeito irá claramente sufocar. Mais adiante no texto, ele afirma que é dessa reserva de atributos que o sujeito deverá forjar um lugar. 
A partir daí, podemos pensar o investimento narcísico dos pais como aquilo que dá um lugar à criança no campo do Outro, o lugar dos significantes que abarcam o sujeito. A partir de um referencial simbólico, o sujeito construirá sua imagem, aquilo que deverá ser segundo sua fantasia - para ser amado, para corresponder à alteridade. Trata-se da constituição do que Freud chamou de eu ideal (Ideal-Ich), Ideal do eu (Ich-Ideal) e supereu (Über-Ich), e o psicanalista Antonio Godino Cabas (1982) agrupou sob o nome de aparelho identificatório.

\section{Eu ideal, Ideal do eu}

Ainda no texto sobre o narcisismo, Freud (2004) levanta a questão: por que a vida psíquica é forçada a ultrapassar as fronteiras do narcisismo e investir a libido nos objetos? Sua resposta apoia-se na perspectiva econômica: se o investimento libidinal no eu torna-se excessivo, ocorre o desprazer como expressão de maior tensão. Ele compara esse processo aos versos do poeta alemão Heinrich Heine sobre a criação do mundo: Foi a doença que causou/Meu ímpeto para criação;/E criando pude ficar são,/E criar foi que me salvou.

No entanto, como foi dito anteriormente, apenas uma parte da libido é investida nos objetos, enquanto a outra permanece direcionada ao eu, como em uma balança. O que é feito, então, dessa libido que originalmente se direcionava ao eu e não foi enviada aos objetos, quando a completude e perfeição infantis se esvaem? Para responder à pergunta, Freud (2004) afirma que o sujeito erige em si um ideal, para onde se dirige o amor antes desfrutado pelo eu infantil (e real). Incapaz de renunciar à satisfação já desfrutada, o ser humano tenta recuperá-la sob a forma de um eu ideal: "Assim, o que o ser humano projeta diante de si como seu ideal é o substituto do narcisismo perdido de sua infância, durante a qual ele mesmo era seu próprio ideal" (Freud, 2004, p. 112).

Ao aumentar as exigências do eu, a formação de ideal é o mais forte favorecedor do recalque (Freud, 2004), relação que interroga o papel dos ideais no assentimento do sujeito a suas exigências pulsionais e na sustentação de seu desejo.

Em seu seminário sobre os escritos técnicos de Freud, Lacan (2009) debruça-se sobre o estudo do narcisismo e diferencia o Ideal-Ich (eu ideal) do Ich-Ideal (Ideal do eu), apostando no rigor da escrita freudiana, já que os dois termos foram utilizados. No ensino de Lacan, o eu ideal é uma instância imaginária, a imagem no espelho, uma projeção. Para que essa imagem se constitua, no entanto, é necessário que o olho, no esquema óptico, esteja em certa posição em relação ao espelho, ou seja, que o sujeito se situe em uma 
posição no simbólico. O modelo simbólico que guiará essa projeção é o Ideal do eu, que se constitui em uma introjeção.

Para descrever a articulação entre esses dois planos de ideal, Lacan lança mão de duas figuras clínicas: o filhinho de papai e a jovem que chama de Marie-Chantal. O primeiro, um rapaz de boa família, às vezes dirige de forma arriscada seu carro esportivo e o faz não sem objeto, mas para conquistar uma garota. Já o segundo personagem é Marie-Chantal, a militante que se inscreve no partido comunista para chatear o pai.

Nos dois casos, os personagens fazem alguma coisa, fazem "um gênero", identificando-se enquanto playboy e enquanto militante comunista. Essa imagem corresponde ao eu ideal, e depende da função simbólica garantida pela introjeção da imagem paterna, da função que exerce o ideal do eu. Não é preciso que os jovens de que Lacan fala estejam colados a seus ideais, que acreditem cem por cento neles. A identidade que o playboy assume como sendo dele depende menos de haver uma garota a se conquistar, e mais do fato de que ser o filhinho localiza-o em relação ao significante pai, cuja reprovação é narcisicamente vantajosa, tanto quanto a aprovação, à medida que sustenta o ideal paterno. No caso da militante comunista, sua escolha parece depender da contrariedade que exerce sobre o pai, do ideal do eu que regula sua organização subjetiva (Lacan, 1960-61/2010; Barros, 1997).

Voltemos à imagem de Agassi, daquele menino que transgredia regras, odiava jogar tênis $e$, ainda assim, tinha um ótimo desempenho, e tomêmo-la como seu eu ideal. Essa imagem parecia depender da contrariedade que provocava no pai, em seu treinador e em todos aqueles de quem, como supôs sua fantasia, o desejo era que ele fosse o tenista número um mundo. Havia, portanto, um guia, o Ideal do eu, que comandava sua posição imaginária. Ou seja, a regulação pelo Ideal do eu permitia que ele hesitasse e transitasse em uma certa contrariedade em relação ao pai. Ao mesmo tempo em que protestava, Agassi obedecia àquilo que considerava ter sido imposto a ele.

\section{Supereu, a instância que fala}

Ao lembrar dos longos e intensos treinos de sua infância, Agassi fala principalmente da voz de seu pai, expressa quase sempre em gritos que lhe davam ordens sobre como rebater as bolas e o condenavam quando ele cometia algum erro (Agassi, 2010). Ao falar sobre os efeitos desses gritos, o tenista parece já anunciar o que Freud (2006b) chamou de uma identificação bem-sucedida com a instância parental - a instauração do supereu: 
"Depois de anos ouvindo meu pai berrando na minha cabeça por causa dos meus erros, bastou uma derrota para eu assumir o discurso dele. Eu tinha internalizado meu pai - sua impaciência, seu perfeccionismo, sua fúria - até que a voz dele não parece a minha: é a minha voz. Não preciso mais dele para me torturar. Desse dia em diante, eu mesmo posso fazer isso sozinho" (Agassi, 2010, p.54).

A primeira aparição do termo supereu, Über-Ich, na obra freudiana ocorre em 1923 no texto $O$ eu e o Id (2007). No entanto, reconhecemos que essa instância já era apontada por Freud desde 0 texto sobre o narcisismo. Lá, ele descreve uma "instância psíquica especial" (2004), a qual atuaria a partir do Ideal do eu, exigindo a satisfação narcísica e, ao mesmo tempo, observaria o eu e o mostraria, ininterruptamente, o quão distante ele (o eu) está desse ideal. Essa instância censora ainda não nomeada funcionava não apenas para fazer cumprir o ideal, mas também para mostrar ao eu que ele, inevitavelmente, falhara em relação ao ideal. A clínica das psicoses é pertinente quanto a esse aspecto, pois aponta para a atividade dessa instância censora no delírio de estar sendo observado, frequente nos quadros paranoides. Mais tarde entendida como uma das funções superegoicas, a consciência moral é instaurada a partir da incorporação da crítica parental e da sociedade, que se apresenta como "uma intrusão hostil oriunda do mundo externo" (FREUD, 2004, p.114).

No momento em que finalmente introduz o termo supereu, Freud (2007) afirma que tal instância está menos vinculada à consciência do que se pensava. Se a princípio o supereu tem sua origem no declínio do complexo de Édipo - enquanto um precipitado no eu, resultado da identificação às autoridades parentais - conforme avançamos na teoria freudiana, desvela-se o estreito vínculo do supereu ao isso.

Enquanto que na primeira tópica o supereu estava mais associado à moralidade e à censura, como a instância que adequa os ideais da cultura segundo o princípio de realidade, a partir de $O$ eu e o isso surge o componente mais pulsional do supereu, com seu estreito vínculo ao isso (Cordeiro \& Bastos, 2011). Por dar cada vez mais ênfase à vinculação pulsional do supereu, em $O$ mal-estar na civilização, de 1930 (2011), Freud afirma que a agressividade do supereu não se deve apenas à introjeção da autoridade parental, o que se confirma pela inexistente correlação entre a severidade do supereu e a severidade do tratamento dado pelos pais. A agressividade dessa instância é, principal e originalmente, fruto da pulsão de morte, e tem menos a ver com a identificação ao pai do que se pensava. 
Em seu retorno a Freud, Lacan definirá o supereu como "uma instância que fala, quer dizer, uma instância simbólica" (Lacan, 2009, p. 180), e atribuirá maior valor ao aspecto pulsional dessa instância, aspecto que ultrapassa a voz proibitiva e se apresenta como voz imperativa. A lei do supereu é uma lei insensata, que não só proíbe o gozo, mas o incita (Lacan, 2009).

Sobre a diferenciação entre o supereu e o Ideal do eu, recorremos ao próprio Freud, que, em uma das Novas Conferências Introdutórias de 1933, A dissecção da personalidade psíquica, estabelece que o supereu é, em uma de suas funções, veículo do Ideal do eu. As demais funções que ele atribuiu a essa instância foram a consciência moral e a auto-observação. Para Barros (1997), a diferença entre supereu e Ideal do eu se dá pelo comando superegoico, insensato e sem sentido, e que, ao contrário do Ideal do eu, não serve como modelo. Apesar de ambos terem origem simbólica, eles se diferenciam em suas funções. Enquanto relacionamos o Ideal do eu com a lei, ou com a introjeção da autoridade parental, a ferocidade e a tirania do supereu se devem a uma quebra do próprio modelo simbólico.

No trecho a seguir, Agassi volta a falar de sua divisão, da contradição entre odiar o tênis e praticá-lo de forma intensiva e satisfatória, contando que desde o início pensava em abandonar o esporte, mas simplesmente não conseguia:

"Tenho sete anos e falo sozinho porque estou assustado e porque sou a única pessoa que escuta o que eu digo. Bem baixinho, digo para mim mesmo: desista, Andre, apenas desista. Largue a raquete e saia desta quadra de uma vez, agora. (...) Mas eu não consigo fazer isso. Não só meu pai me perseguia pela casa, me ameaçando com a minha própria raquete, como alguma coisa dentro de mim, algum músculo lá no fundo de mim, não me deixa fazer isso. Eu detesto jogar tênis, detesto de todo o meu coração, mas continuo jogando, batendo bola todas as manhãs e todas as tardes, porque não tenho escolha. Não importa o quanto eu queira parar, não consigo. Continuo implorando a mim mesmo para parar, mas sigo na quadra, e esse descompasso, essa contradição entre o que eu quero fazer e o que eu realmente faço, parece ser o centro da minha existência" (Agassi, 2010, p. 39).

\section{A título de conclusão}

O relato parece trazer a insistência da pulsão de morte, o imperativo de gozo superegoico. Desde os sete anos de idade, sofrer jogando tênis era imperativo, algo que Agassi localizava nele próprio, "como 
um músculo lá no fundo". Como ele mesmo lembra, poderia estar brincando com os irmãos ou assistindo à televisão com a mãe, mas era impossível desobedecer à intimação.

É por esse motivo que precisamos pensar para além do narcisismo parental em nossa práxis. Se encaminhássemos a questão apenas por essa via, estaríamos localizando e esgotando a função do Outro em pessoas concretas - nesse caso, no pai do tenista. O Outro é sempre uma construção da fantasia, e também o lugar da alteridade, de onde se pode desejar. É por esse motivo que o trabalho da análise deve esvaziar esse Outro fantasmático e seus imperativos, sem favorecer a idealização - facilitadora do recalque -, para permitir que o sujeito se encontre com seu próprio desejo (Cottet, 1995).

Os limites que o estudo de um testemunho desta natureza coloca para o psicanalista não permitem prosseguir na direção da fantasia inconsciente que sustenta o desejo. Assim, somos levados a enunciar a necessidade de revisitar conceitos e, a partir da experiência psicanalítica propriamente dita, recolocá-los frente aos ideais de performance e consumo característicos de nossos tempos.

\section{Referências}

Agassi, A. (2010). Agassi: autobiografia. (1a ed., H. Londres, R. Ziegelmaier, S. Mourão, trad.). São Paulo: Globo.

Barros, R. R. (1997). Eu ideal, ideal do eu e o resto. Latusa - Escola Brasileira de Psicanálise, n. 1, p. 19-33.

Cabas, A. G. (1982). Curso e discurso da Obra de Jacques Lacan. São Paulo: Moraes.

Cordeiro, N. M. L. \& Bastos, A. (2011). O supereu: imperativo de gozo e voz. Tempo psicanalítico, v. 43, II, p. 439-457. http://pepsic.bvsalud.org/scielo.php?pid=S010148382011000200011\&script=sci_arttext

Cottet, S. A interpretação incide sobre a causa do desejo. Conferência de encerramento do Colóquio "Problemas atuais da interpretação em psicanálise". EBP-São Paulo, 27/08/1995.

Freud, S. (2004). À guisa de introdução ao narcisismo. In: Freud, S. Escritos sobre a psicologia do inconsciente. (L. A. Hanns, trad., Vol. 1, pp. 95-131). Rio de Janeiro: Imago. (Trabalho original publicado em 1914).

Freud, S. (2006a). Notas psicanalíticas sobre um relato autobiográfico de um caso de paranoia (dementia paranoides). In Freud, S. Edição standard brasileira das obras psicológicas completas de Sigmund Freud, v. XII. (pp. 14-89). Rio de Janeiro: Imago. (Trabalho original publicado em 1911).

Freud, S. (2006b). Conferência XXXI: A dissecção da personalidade psíquica. In Freud, S. Edição standard brasileira das obras 
psicológicas completas de Sigmund Freud, v. XXII. (pp. 63-84). Rio de Janeiro: Imago. (Trabalho original publicado em 1933).

Freud, S. (2007). O Eu e o Id. In Freud, S. Escritos sobre a psicologia do inconsciente. (L. A. Hanns, trad., Vol. 3, pp. 13-71). Rio de Janeiro: Imago. (Trabalho original publicado em 1923).

Freud, S. (2011). O mal-estar na civilização. São Paulo: Penguin Classics Companhia das Letras. (Trabalho original publicado em 1930).

Lacan, J. (1998). Observação sobre o relatório de Daniel Lagache: "Psicanálise e estrutura da personalidade". In: Escritos. (pp. 653-691) Rio de Janeiro: Jorge Zahar. (Trabalho original publicado em 1963).

Lacan, J. (2009). O seminário, livro 1: os escritos técnicos de Freud. Rio de Janeiro: Jorge Zahar. (Seminário ministrado em 1953/1954).

Lacan, J. (2010). O seminário, livro 8: a transferência. Rio de Janeiro: Jorge Zahar. (Seminário ministrado em 1960/1961).

\section{Endereço para correspondência \\ Andréa Di Pietro Lewkovitch}

Consultório particular

Av. Paisagista José Silva de Azevedo Neto, 200, Bloco 06, Sala 207, Barra da Tijuca, CEP 22740-361, Rio de Janeiro - RJ, Brasil

Endereço eletrônico: andreadipietro2@gmail.com

\section{Angélica Bastos de Freitas Rachid Grimberg}

Universidade Federal do Rio de Janeiro

Instituto de Psicologia

Avenida Pasteur, 250, Pavilhão Nilton Campos, Praia Vermelha, CEP 22290-902, Rio de Janeiro - RJ, Brasil

Endereço eletrônico: abastosg@terra.com.br

Recebido em: 25/08/2015

Aprovado em: 26/12/2016

\section{Notas}

* Mestre em Teoria Psicanalítica pelo Instituto de Psicologia da Universidade Federal do Rio de Janeiro.

** Psicanalista. Professora Associada no Programa de Pós-graduação em Teoria Psicanalítica da Universidade Federal do Rio de Janeiro. Bolsista de Produtividade em Pesquisa do CNPq. Membro da Escola Brasileira de Psicanálise e da Associação Mundial de Psicanálise. 